IMDS

117,9

1890

Received 31 October 2016 Revised 18 February 2017 Accepted 23 March 2017

\section{Modeling of an IoT-enabled supply chain for perishable food with two-echelon supply hubs}

\author{
Yingfeng Zhang and Lin Zhao \\ Northwestern Polytechnical University, Xi'an, China, and \\ Cheng Qian \\ Department of Industrial Engineering, \\ Northwestern Polytechnical University, Xi'an, China
}

\begin{abstract}
Purpose - The huge demand for fresh goods has stimulated lots of research on the perishable food supply chain. The characteristics of perishable food and the cross-regional transportation have brought many challenges to the operation models of perishable food supply chain. The purpose of this paper is to address these challenges based on the real-time data acquired by the Internet of Things (IoT) devices.

Design/methodology/approach - IoT and the modeling of the Supply Hub in Industrial Parks were adopted in the perishable food supply chain.

Findings - A conceptual model was established for the IoT-enabled perishable food supply chain with two-echelon supply hubs. The performance of supply chain has improved when implementing the proposed model, as is demonstrated by a case study.

Originality/value - By our model, the supply hubs which act as the dominators of the supply chain can respond to the real-time information captured from the operation processes of an IoT-enabled supply chain, thus to provide public warehousing and logistic services.

Keywords Internet of Things, Conceptual model, Supply chain for perishable food, Two-echelon supply hubs Paper type Research paper
\end{abstract}

\author{
Nomenclature \\ $d_{l j} \quad$ Quantity of product $j$ ordered by retailer $l ; S_{i j}$ \\ $D_{j} \quad$ Total demanded quantity of product $j$; \\ $R_{k} \quad$ Demanded quantity for material $k$; \\ $a_{i j} \quad$ Quantity of raw material $i$ used to \\ produce product $j$; \\ $x_{i j} \quad$ Quantity of product $j$ in the order \\ assigned to processor $i$; \\ $y_{i j} \quad$ Quantity of product $j$ in the order that \\ processor $i$ subjectively applies for;
}

The satisfactory of processor $i$ for getting the order of product $j$;

$w_{i j} \quad$ A positive weight assigned to product $j$ of processor $i$;

$\lambda_{i} \quad$ A positive weight assigned to processor $i$;

$C_{i j} \quad$ The cost of supply chain when processor $i$ produces product $j$.

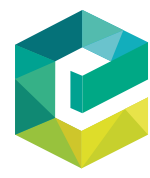

Industrial Management \& Data Systems

Systems
Vol. 117 No. 9, 2017 pp. $1890-1905$ Emerald Publishing Limited 0263-5577

DOI 10.1108/IMDS-10-2016-0456

\section{Introduction}

Millions of people are increasing their spending on fresh, delicious but perishable and expensive goods like fruits, seafood, etc. According to the AQSIQ Statistics Report, the demand for salmon (which is a kind of popular seafood) imported to China has increased

\footnotetext{
(C) Yingfeng Zhang, Lin Zhao and Cheng Qian. Published by Emerald Publishing Limited. This article is published under the Creative Commons Attribution (CC BY 4.0) licence. Anyone may reproduce, distribute, translate and create derivative works of this article (for both commercial \& non-commercial purposes), subject to full attribution to the original publication and authors. The full terms of this licence may be seen at: http://creativecommons.org/licences/by/4.0/legalcode
} 
from 74 thousand tons in 2003 to 283.8 thousand tons in 2013 (www.aqsiq.gov.cn/zjsj/tjxx/tjsj/). The huge demand for perishable food has stimulated the development of many related profit-making industries greatly, e.g., the cultivating, processing, and transportation of the perishable products. These activities are connected throughout the operations of the supply chain for perishable food (SCPF).

Nowadays, the supply chain revolution is reshaping a lot of industries through reconsidering the organizations, people, activities, information, and resource flow which are involved in moving a product or service from supplier to customer as a system (Bowersox et al., 2007). The supply chain management implies a highly effective network of business relations that serves to improve efficiency by eliminating duplicate and nonproductive work. Thus, the profit-makers are increasingly paying more attention on the operations of SCPF which is known as the farm-to-fork sequence. These operations are intended to satisfy the huge market demand and expand in market shares, including farming (i.e. land cultivation and production of crops), processing, inspection, packaging, warehousing, transportation, distribution, and marketing (Iakovou et al., 2014).

However, the performance of SCPF is frequently challenged by the characteristics of perishable food and the cross-regional logistics activities (Zhang, Wang, and Liu, 2017). The 2008 FMI/GMA Unsaleable Report on perishable food estimated that the total unsaleable goods has increased $\$ 3-\$ 5$ billion in 2010 (Grunow and Piramuthu, 2013). These challenges mainly fell into three categories. The first one is the consumers' decreasing tolerance of the degradation of perishable food. The second one is the possible lack of supervision that may cause the unsaleable goods flow into the market, threatening the consumers' health. The third challenge is the urgent need to reduce the high operational cost of supply chain and to improve the operational efficiency.

Faced with these challenges, the perishable food industry should reconsider the current operational models of supply chain and upgrade the supply chain management systems, so that the supply chains can deal with the unpredictable situations better, and meet the quality requirements for food consistently (Eksoz et al., 2014). In this paper, we analyzed the existing problems and proposed a conceptual model for SCPF to transport perishable goods timely, safely, and economically.

Considering the time value of perishable foods, the cross-regional supply chain operation, and the industrial characteristics of perishable food, some research questions that the SCPF is facing are listed as follows:

$R Q 1$. How to design an overall architecture for the timely circulations of the SCPF operational information and for the dynamic cooperation among different nodes of a supply chain?

$R Q 2$. How to design a conceptual model of supply chains to meet the requirements for industrial operations of perishable food and to quickly respond to market changes under the environment of real-time information sharing?

RQ3. How to design a dynamic optimization method for the order allocation of perishable food to improve the performance of the supply chain?

To address the above challenges and research questions, our research adopted the Internet of Things (IoT) technology and the theory of the Supply Hub in Industrial Parks (SHIPs).

IoT is defined as a dynamic global network infrastructure where objects are connected, monitored, and optimized through either wired, wireless, or hybrid systems (Atzori et al., 2010; Giusto et al., 2010; de Saint-Exupery, 2009). In recent years, the advancement in IoT such as radio frequency identification (RFID), sensor technology, communication modules, microprocessors, and actuators has offered much broader potential in the real-life implementations (Qiu et al., 2015). Specially, sensor technology which can be 
IMDS

117,9

1892

used to intelligently monitor temperature and humidity during transportation has become a primary technique in the transportation of fresh products (Hong et al., 2011).

SHIP is regarded as a public provider of warehousing and transportation services for enterprises located within an industrial park (Li and Qiu, 2014; Qiu et al., 2015; Qiu and Huang, 2013). Cluster of suppliers and processors of SCPF facilitates the SHIP approach to be adopted. The establishment of SHIP which can be regarded as a special scenario of supply chain brings a new transformation and upgrade for industries, as member enterprises in an industrial park could share physical assets and services of SHIP without their own investments.

The rest of this paper is organized as follows. Section 2 reviews the literature related to this research. Section 3 discusses the phenomenon of industry agglomeration in SCPF. Section 4 introduces the model of SCPF with two-echelon supply hubs (SCPF-2ESH), and the overall architecture of IoT in this model is proposed in Section 5. The workflow of task assignment is modeled in Section 6, followed by a case demonstration in Section 7. Section 8 concludes this research and proposes directions for further research.

\section{Literature review}

Three streams of literature are relevant to this research, which include the IoT-based real-time data capturing, the SCPF, and the theory of the SHIPs.

Since first coined by MIT in the late 1990s, IoT has become particularly popular through some potential representative applications (Uckelmann et al., 2011). RFID is a widely used and key enabling technology that is regarded as a prerequisite or essential element in IoT (Atzori et al., 2010) and is broadly adopted in many nodes of supply chain, such as production, warehousing, transportation, etc. Resent research shows that RFID has been successful applied in access control, airport baggage handling, and automated toll collection systems (Ergen et al., 2007; Hou and Huang, 2006; Leung et al., 2014). In the production field, the RFID technology is implemented to provide guidance in the assembly processes under an augmented reality environment (Zhang et al., 2011). Later, a real-time information-capturing and integration architecture of the Internet of Manufacturing Things is proposed (Zhang et al., 2014). Based on the new manufacturing paradigm, the multi-agent-based real-time production-scheduling method, RFID-enabled real-time wireless manufacturing, shop-floor material handling, and some other operation and resource optimization methods are proposed (Zhang et al., 2016; Zhang, Zhang, Qu, Liu, and Zhong, 2017; Zhang, Qian, Lv, and Liu, 2017; Zhang, Wang, Liu, and Qian, 2017; Zhang et al., 2015).

It is only during the last ten years that the perishable food industry has recognized and started embracing supply chains as a key concept for its competitiveness (Tsolakis et al., 2014). Most researchers focus on the operational optimization of supply chains toward problem solving rather than theory developing. An excellent review summarized their works and presented the operational research models applied to the supply chain for fresh fruit (Soto-Silva et al., 2016).

As IoT is wildly used in the supply chain field, and the concept of virtual perishable food supply chains from an IoT perspective is analyzed (Saguy et al., 2013; Porter and Heppelmann, 2014; Denolf et al., 2015). Sensor technologies are used to record the state information over lifecycle of the objects of interest. This may include the monitoring of temperature, microbiological information, and other food quality parameters (Aung and Chang, 2014; Bosona and Gebresenbet, 2013; Zhou and Piramuthu, 2015). More adaptable SCPF models, such as the SCPF model with supply hubs, and the overall architecture of the deployment of IoT in SCPF still lack consideration.

A typical supply hub is defined as a location physically close to a manufacturer's facility where all or some of its supplies are located with the agreement that the materials will be 
paid for only when consumed (Zuckerman, 2000) under a special model of supplier-buyer relationships (Barnes et al., 2003). The proposed SHIP is an extended conception of the supply hub. The value of freight consolidation, benefits of applying the SHIP approach, is evaluated (Qiu and Huang, 2013) and their decisions on storage pricing is also discussed (Qiu et al., 2014). Besides, IoT technology is adopted to SHIP for enhancing the effectiveness and efficiency of sharing physical assets and services (Qiu et al., 2015; Qu et al., 2015).

\section{The industrial agglomeration phenomenon in SCPF}

In the perishable food industry, an interesting phenomenon is that the suppliers and the retailers of SCPF often gather together to form their industrial parks or markets, respectively. From the perspective of industrial organization theory, this phenomenon is called industrial agglomeration. The agglomeration force creates attraction to clusters that maximizes the tendency to co-locate with customers and intermediate good supplies (Baldwin et al., 2012). Generally, industrial agglomeration is considered as the inevitable outcome of economic development and now largely appears in all kinds of industries with the form of industrial parks. As a result, the development of industrial parks has become a critical strategy to promote economic development in many countries (Zhe et al., 2015).

To go with this trend, our research proposes the model of the SHIPs as an approach for driving the operation of SCPF. In the perishable food industry, processors tend to agglomerate in industrial parks which often located in suburban areas with convenient transportation systems and can be regarded as a kind of upgraded trade market.

Unlike the common food, many characteristics of perishable products depend on the specialty of the area where they are produced, such as fisheries, docks, and plantations. Even within neighboring areas, some of the characteristics are topographical dependent. Suppliers often construct their plants around these areas so that the raw materials of perishable products can be quickly cleaned, dried, packaged, and loaded into containers. For the same reason, similar suppliers may gather together and form industrial zones without any policy guidance.

In all, the industry agglomeration phenomenon of both suppliers and processors in SCPF can be regarded as the key features of SCPF. Therefore, the performance improvement of SCPF needs to be considered in an integrated perspective of suppliers and processors.

\section{Modeling of SCPF-2ESH}

In this section, a novel PFSC model is introduced motivated by the trend of development in the present perishable food industry. The logical and information flow of the supply chain is redesigned, where the supply hubs play a dominating role in the supply chain.

\subsection{The SCPF-2ESH model}

Perishable food supply chain is a complex network which is generally composed of retailers, manufactures, and suppliers. In the existing models of SCPF, the products go through the supplier, processors, and retailers before reaching the customers' side. As shown in Figure 1(a), market as traditional transaction place still holds important status in current SCPF with information flow transferring and transmitting. There are two features of the traditional model. First, each participant arranges their logistical activities independently. Second, the information flow moves along the supply chain through many nodes.

As we all know, the operation of SCPF requires stricter standards of storage and transportation. Integrating the operations of logistics and storage can greatly enhance the operational efficiency, thus reducing the cost of logistics operations and increasing the time value of perishable products. The agglomeration of suppliers and processors promotes the SHIP to be adopted to improve the operational performance of supply chains. Compared to the current SCPF model, a novel supply chain model with $2 \mathrm{ESH}$ which dominate the 
IMDS

117,9

1894

Figure 1.

Comparison between the two SCPF models (a)

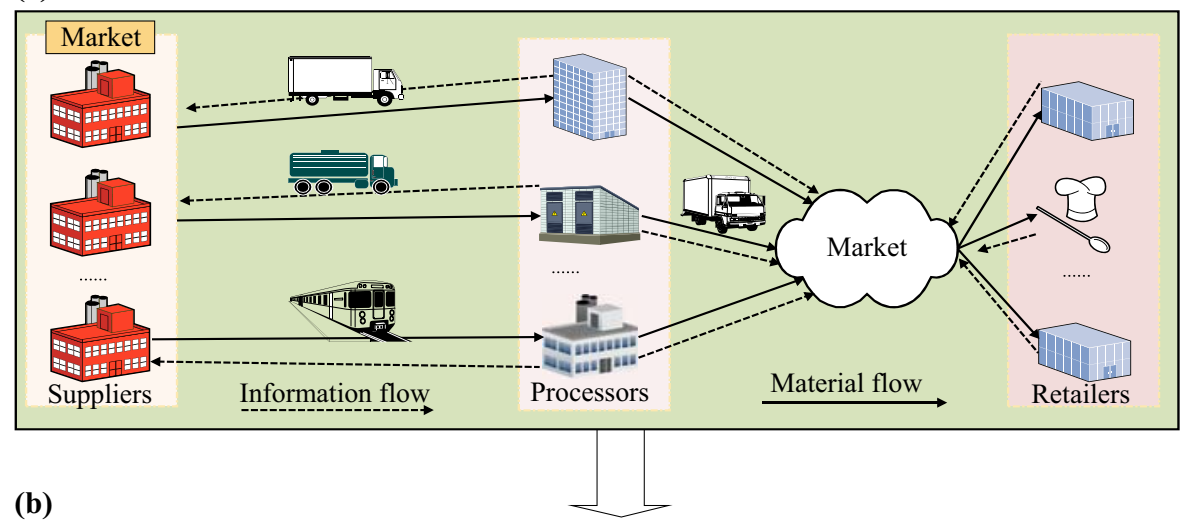

(b)

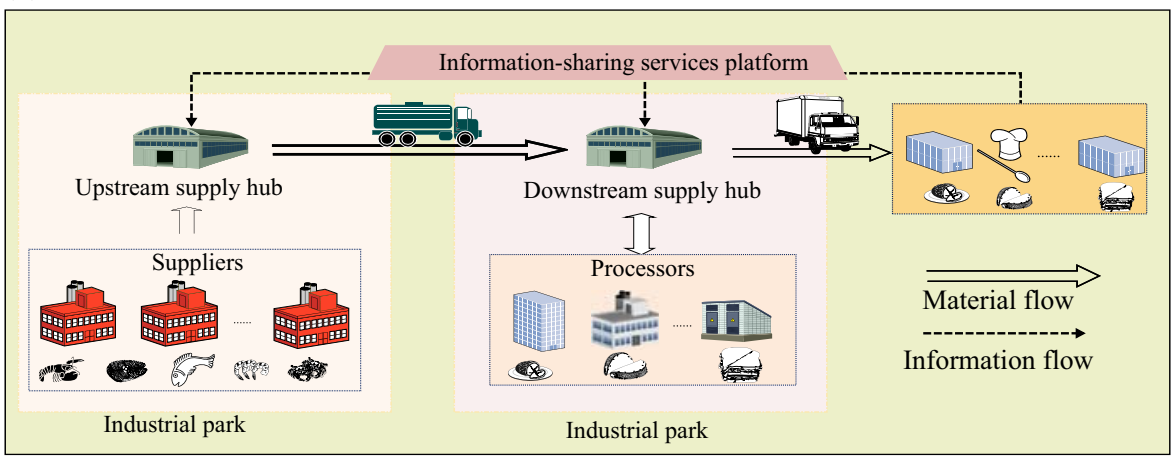

Notes: (a) The traditional SCPF model; (b) the SCPF model with two supply hubs

operations of SCPF is designed. Figure 1(b) illustrates the simplified but insightful SCPF model to optimize the operations in the supply chain. The model consists of suppliers, supply hubs (the upstream and the downstream supply hubs), manufactures, and retailers. According to the geographical proximity, the upstream and downstream supply hubs can not only provide logistics and storage services but also respond to the events occurring during the SCPF operations, respectively.

\subsection{Capabilities of the supply hubs}

In our model, supply hubs are regarded as SCPF dominators and can provide the following services.

First, the supply hubs can provide the public logistic service which is responsible for the transportation, distribution, and storage for their neighboring partners. The upstream supply hub provides temporary storage service and collects many kinds of materials according to the orders. The downstream supply hub provides storage service for raw materials, intermediate product, and products, and it is also in charge of the shipment and distribution activities.

Second, the service of the real-time online logistics monitoring is also provided. Based on the modern communication and sensor technologies, the real-time status of products in operational processes can be monitored and traced. The supply hubs thus can provide help or independently deal with some incidences during the operational processes of SCPF. 
Third, the supply hubs can provide the online quality monitoring services. The real-time parameters for quality control of products in the processes of SCPF are captured by the supply hubs. Once a potential disturbance is detected, the supply hub can respond quickly and inform the frontline enterprises. After that, the supply hub pays more attention on the relevant processes of the disturbance and adjusts the operation plans until the processes resume normal.

Another highlighted feature of the model of SCPF-2ESH is its real-time information-sharing mechanism. The model provides a cloud service platform in which retailers' orders cluster together so that the processors and suppliers can acknowledge the requirements from the retailers at the same time. Then, the bullwhip effect of supply chains can be greatly mitigated.
Modeling of an IoT-enabled SCPF-2ESH

1895

\subsection{The material flow in SCPF-2ESH}

The material flow in SCPF is composed of a series of logistics activities including transportation, storage, distribution, etc. Since this paper mainly focus on the operational processes in SCPF, the internal logistics activities within each production cell are temporarily ignored. After the demand for raw materials is published, the logistics activities of SCPF can see a logistics system initiate. The logistics processes of SCPF is shown in Figure 2, where five production cells are involved in this case (i.e. the suppliers, the upstream supply hub, the downstream supply hub, the processors, and the retailers). As mentioned above, the supply hubs act as the pivots of logistics activities and drive the operations of SCPF. Supplies produce raw materials according to the orders. Upstream supply hub provides storage services.

\section{Overall architecture of the deployment of IoT in SCPF-2ESH}

The real-time traceability and visibility of supply chain processes play a critical role in improving the performance of SCPF. This section aims to apply the concept of IoT to the SCPF field and to build up a real-time information-capturing and integration reference architecture for SCPF-2ESH. By implementing the infrastructure of IoT, an overall architecture for the real-time information capturing and integration of the IoT-enabled SCPF is designed in Figure 3. Under this architecture, the real-time tracking and tracing of the supply chain can be achieved. Then, the execution processes of the whole supply chain can be dynamically monitored. The sensor networks are used to measure the dynamic parameters such as environment (e.g. temperature, pressure, humidity, etc.), movement (e.g. velocity, vibration, etc.), and the real-time status of manufacturing things.

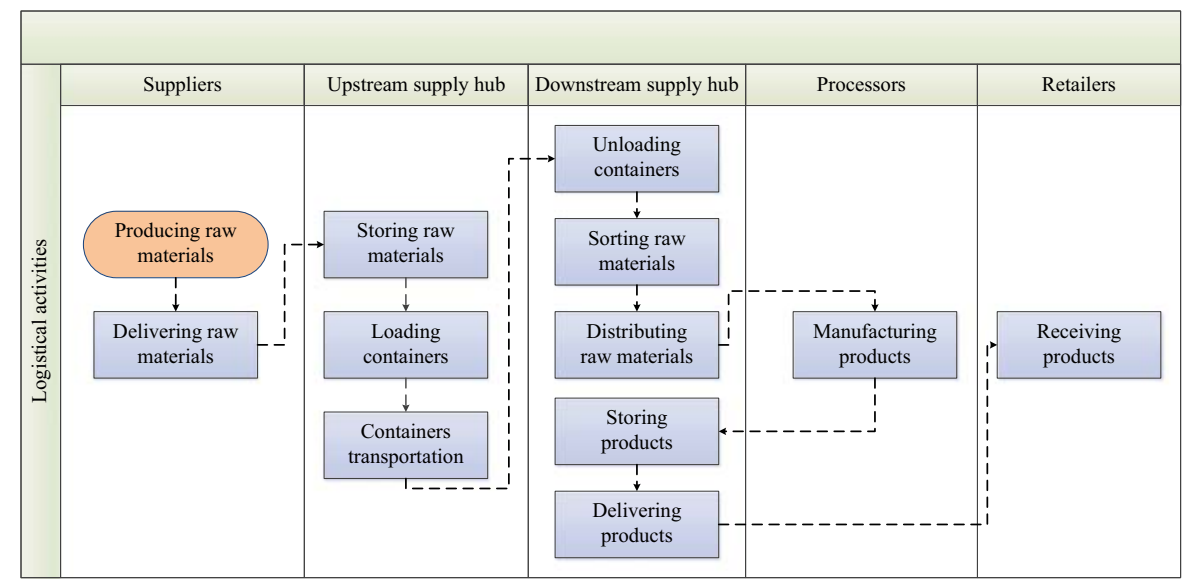

Figure 2.

The logistics processes in SCPF-2ESH 
IMDS

117,9

1896

Figure 3.

Overall architecture of the deployment of IoT in SCPF-2ESH
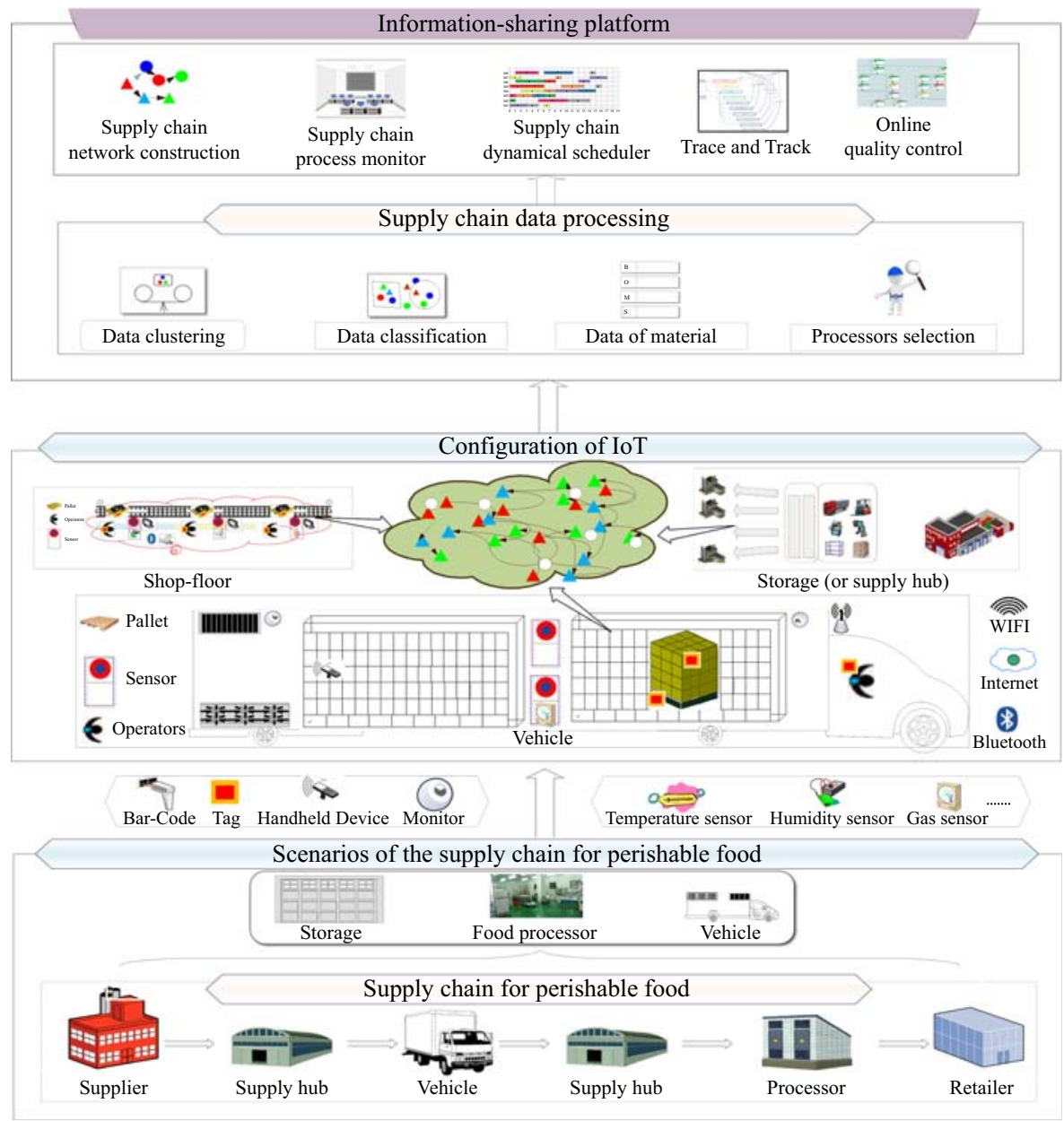

The architecture provides the supply hubs (also known as the dominators of SCPF) with real-time information to drive the operations of SCPF.

The architecture of SCPF consists of four layers from bottom to top, namely the resource layer, the perception layer, the data processing layer, and the layer of the information-sharing service. They are described as follows.

The resource layer includes various resources of supply chains which are involved in the supply chain lifecycle, including retailers, manufactures, suppliers, etc. Generally speaking, the status of the perishable food falls in one of the following three scenarios, i.e., being stored in storage, being processed by a food processor, or being transported in vehicles. In this research, the resource layer concentrates on the deployment of multiple sensors in the three scenarios.

Perception layer is responsible for improving the sensing capability of the resources in supply chain. The static descriptive information can be derived from the inherent attributes of resources and the dynamic sensing information can be achieved by equipping the physical resources of the supply chain with IoT devices, such as RFID readers, temperature sensors, handed monitoring devices, humidity sensors, gas sensors, etc. 
Through these devices, the resources of the supply chain can jointly form a communication Modeling of an network, and the information can be shared among different members of the supply chain if they are authorized to access to the information.

The data processing layer is responsible for processing the orders in the supply chain, which focuses on data clustering, data classifying, the management of the bill of materials, and the assignment of orders to processors. The orders from retailers are accumulated over time. Through a series of processes, the lists of demand for products and raw materials are obtained. Thanks to the IoT technologies, the downstream supply hubs can have access to more information about the processors. This can mitigate bullwhip effect. These benefits bring to SCPF are discussed later.

$\mathrm{SCPF}$ is a complex system which involves multiple entities. The information services platform enables the supply chain to share information among different entities. Here, four types of services, namely the process monitor service, the supply chain reengineering service, the dynamical scheduler service, and the online quality control service, are included in this framework. The real-time data of the manufacturing things provide important information for these services.

\section{The workflow of order assignment in an IoT-enabled SCPF-2ESH}

The fulfillment of real-time information capturing and sharing can effectively mitigate the bullwhip effect generated during the supply chain operations and can reduce information asymmetry among nodes of supply chain. Unlike the relatively stable partnerships in the upstream supply hubs, different processors may participate in the operations of supply chain in different time period of the order. Based on the IoT technologies, the downstream supply hubs can gather information from the processors and take orders in place of the processors. Retailers who have demand for products should register and publish orders to the downstream hubs. Their orders should specify the required type, amount of products, etc. Different orders are quickly aggregated or decomposed on the information services platform, and the related information will be shared between the two supply hubs. Once receiving the shared information of the orders, the upstream supply hub will organize suppliers to prepare the necessary raw materials to fulfill the orders, as required by the downstream supply hubs. To realize this workflow, a processors' satisfaction model is presented as follows. The notations of the model are defined in "Nomenclature."

The aggregate demand of product $j$ in SCPF-2ESH is obtained as follows:

$$
D_{j}=\sum_{l=1}^{k} d_{l j}(j=1,2, \ldots, m)
$$

\subsection{The model of processors' satisfactory}

The ideal production quantity of product $j$ for processor $i$ is $y_{i j}^{*}$, and the least acceptable production quantity is $y_{i j}^{0}$. Therefore, quantity interval $\left[y_{i j}^{0}, y_{i j]}^{*}\right]$ is the range that processor $i$ applies to downstream supply hubs for undertaking the task of product $j . s_{0}$ is the basic satisfaction degree that the processor has a critical motivation to accept the orders and processor $i$ would not consider the orders whose quantity is less than $y_{i j}^{0}$. In addition, the most desirable quantity of orders is $y_{i j}^{*}$, where the processor achieves the greatest satisfactory. The greatest satisfactory is defined as 1 (or 100 percent).

The aforementioned problem is formulated as the piecewise function (1). Parameters $y_{i j}^{s}, y_{i j}^{0}, y_{i j}^{\max }, y_{i j}^{e}$ is exogenous. Within the quantity interval $\left[y_{i j}^{s}, y_{i j}^{e}\right]$, processor $i$ has a positive satisfaction degree to produce product $j . y_{i j}^{s}$ and $y_{i j}{ }^{e}$ are the thresholds of the satisfaction degree. Without loss of generality, we suppose that $S_{0}$ is a constant for each processor. 
IMDS 117,9

1898
In real-world situations, processors have ordering preference for products they can produce. Thus, weight $w_{j}(j=1,2, \ldots, m)$ is used to prioritize the preference. We assume that each processor has the same weight. Thus, a linear weighted sum function is presented to represent the satisfactory of processor $i$. The function, as shown in Figure 4 is $S_{i}=\sum_{j=1}^{m} w_{j} S_{i j}\left(x_{i j}\right) \quad(i=1,2, \ldots, n)$, where:

$$
S_{i j}\left(x_{i j}\right)= \begin{cases}0 & x_{i j} \in\left(0, y_{i j}^{s}\right) \cup\left(y_{i j}^{e},+\infty\right) \\ \frac{x_{i j}-y_{i j}^{s}}{y_{i j}-y_{i j}^{s}} & x_{i j} \in\left(y_{i j}^{s}, y_{i j}^{0}\right) \\ S_{i j}^{0} & x_{i j}=y_{i j}^{0} \\ S_{i j}{ }^{0}+\frac{x_{i j}-y_{i j}^{0}}{y_{i j}^{\max }-y_{i j}^{0}}\left(1-S_{i j}^{0}\right) & x_{i j} \in\left(y_{i j}^{0}, y_{i j}^{\max }\right) \\ 1 & x_{i j}=y_{i j}^{\max } \\ \frac{x_{i j}-y_{i j}^{\max }}{y_{i j}{ }^{\max }} & x_{i j} \in\left(y_{i j}^{\max }, y_{i j}^{e}\right)\end{cases}
$$

\subsection{The model of order assignment}

In order to get an optimal allocation of orders, two objective functions are taken into consideration. One aims to minimize the operation cost, and the other one focuses on maximizing the satisfactory of processors. Sharing real-time information of production processes expands the monitoring scope of supply chain. Then, the information asymmetry between different roles in the supply chain is turned into information symmetry. In the case of information symmetry, the evaluation criteria for choosing suppliers is relatively normative, thus tend to come up with an optimal solution.

The first objective function is to minimize operational cost of the supply chain, which is denoted by $Z_{0}$. The function is formulated as $Z_{0}=\sum_{i=1}^{n} \sum_{j=1}^{m} C_{i j} x_{i j}$, where $C_{i j}$ is the processor $i$ 's bid to producing per product $j$. We suppose that the volume discount is ignored for supply hubs that provide storage and logistics services.

For other objective functions, we introduced a weight to distinguish the importance of a processor. Since the IoT environment makes it possible to monitor all operations of the supply chain, the performance of processors becomes less vital in some extent, as their operations must meet the minimum quality requirement and can be monitored online. Despite that, from a perspective of the strategic development of the supply chain, it is still necessary to model the importance of each processor. Weight $\lambda_{i}(i=1,2, \ldots, n)$ is used to measure the strategic importance of processor $i$ (Korpela et al., 2002) where $\sum_{i=1}^{n} \lambda_{i}=1$. So, the total supply chain satisfaction is $Z_{1}=\sum_{i=1}^{n} \sum_{j=1}^{m} \lambda_{i} w_{j} S_{i j}\left(x_{i j}\right)$.

Figure 4.

The relations between the processors' satisfactory and the quantity of orders

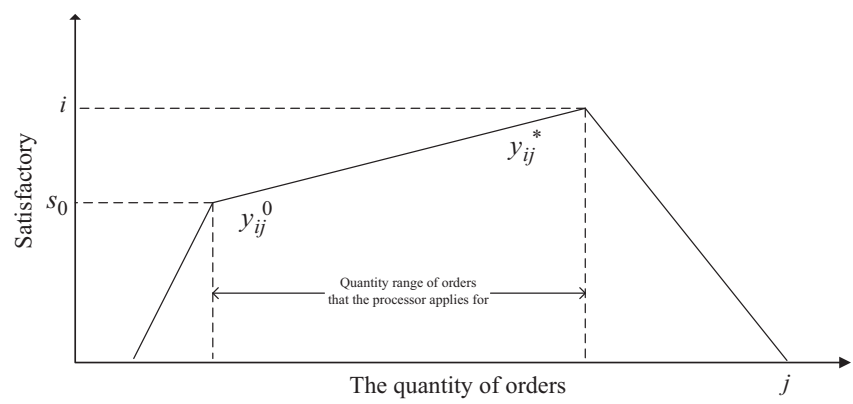


The objective function is obtained as follows:

$$
\begin{aligned}
\min Z_{0} & =\sum_{i=1}^{n} \sum_{j=1}^{m} C_{i j} S_{i j}\left(x_{i j}\right), \\
\max Z_{1} & =\sum_{i=1}^{n} \sum_{j=1}^{m} \lambda_{i} w_{j} S_{i j}\left(x_{i j}\right),
\end{aligned}
$$

Subject to:

$$
\begin{gathered}
\text { s.t. } D_{j}=\sum_{i=1}^{n} x_{i j}=\sum_{l=1}^{k} d_{l j} \\
x_{i j} \geqslant 0 \\
i=1,2, \ldots, n ; \quad j=1,2, \ldots, m .
\end{gathered}
$$

The above model is a multi-objective programming problem, and the two objectives collide with each other. The liner weighted method is used to merge (2) and (3) into the following equation:

$$
\max Z=o_{1} Z_{1}-o_{2} Z_{0}
$$

where $o_{1}, o_{2}$ is the weight of $Z_{1}, Z_{0}$. Many methods such as genetic algorithms approach or ant colony algorithms approach can optimize the programming problem.

\section{Case study}

In this section, a case demonstration of the SCPF-2ESH model is analyzed to illustrate how the proposed model was introduced to a company to upgrade its strategy of supply chain management. In addition, lessons learnt from the case are drawn in a normative manner for the effective implementation of SCPF by other companies in similar situations.

\subsection{Introduction of the case company}

The case company has an integrated industrial park that provides logistics service for agricultural products. The company lies in the Yangtze River Delta of China and ranked the top one of that field in Jiangsu province. The industrial park has been creating over 20 billion RMB annual transactions since 2011. As shown in Figure 5, the industrial park is located near the Beijing-Shanghai Railway, the Shanghai-Nanjing Expressway, the Yangtze River Highway, the No. 312 State Road, and the Jing-Hang Canal. It is ten kilometers away from the city downtown and 16 kilometers away from the airport. Currently, this company is specialized in aquaculture, fresh fruit, vegetable, etc. It also provides logistics service not only for the merchants within the industrial park, but also for the public demand.

Originally, this industrial park was built as a vegetable wholesale market. Nevertheless, the convenience of transportation has stimulated its extension of business scopes. As a result, an increasing number of merchants entered the market and many agricultural products were transported to the market. Large volume of business has led to the large-scale logistics activities. Logistics management and logistics optimization, such as eliminating the idle load, joint inventory, etc., became big challenges to the managers of the market. As the market share in logistics increased, the market laid down the logistics service as another dominating business. 


\section{IMDS}

117,9

\section{0}

Figure 5.

The location of the case company

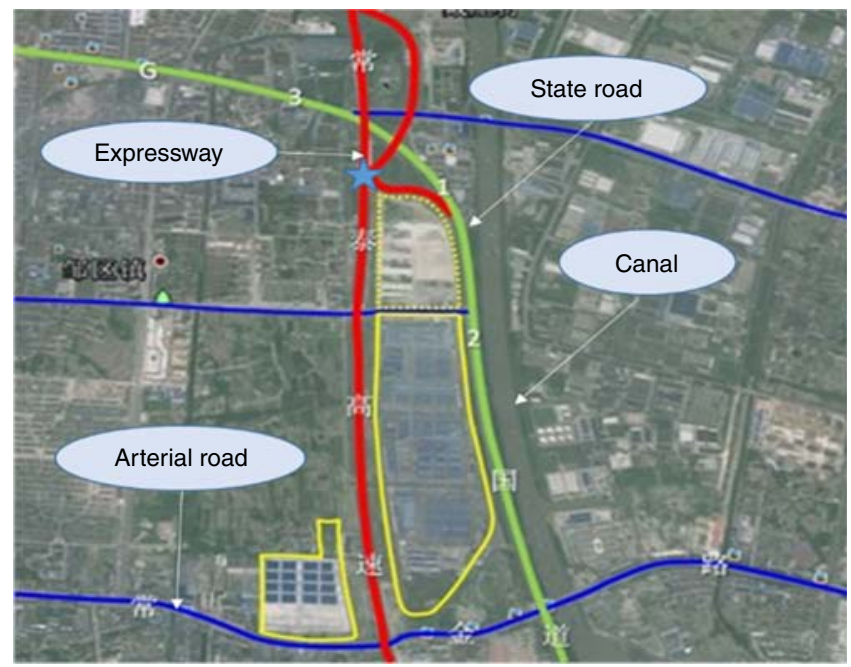

Through surveys and interviews with senior managers of the case company, the problems of the industrial park are summarized as follows:

- The industrial park has its own information-sharing platform, but the function of the platform is limited. The underutilized information platform only publishes transportation information of vehicles in the logistics field. Although the industrial park regularly launches the agricultural index, e-business, such as online purchase, online order, etc., has not been implemented.

- The industrial park provides conditional public storage service for its merchants. The only storage service they prove is to rent the storage. They do not provide logistics services for products with small volume, nor do they have any management services. This is not beneficial for the cost decrease and efficiency improvement, especially in the freezer storage field.

- Each merchant manages its transportation and delivery activities independently, which does not belong to the responsibility of the industrial park. In particular, the potential risk of the perishable food going bad prevents the industrial park from being the dominator in the cold chain logistics, which may be the most qualified candidate to coordinate all processes of logistics.

- The supply chain only process limited kinds of products, such as ginger, garlic, etc. The brand advantages of this industrial park guarantee the long-term and stable relationship between upstream suppliers and downstream retailers. However, the industrial park does not participate in the operations of SCPF and has no willingness to go into this field.

\subsection{Application in the case company}

Confronting these problems, managers of this industrial park attempt to tailor and reconstruct the supply chain, especially the perishable food supply chain. As to the question whether to maximize the supply chain surplus (Kim et al., 2014) or to minimize the operational cost of the supply chain, the proposed model can help with the business process reengineering (Davenport, 1995) of the industrial park. Based on the proposed model, the general procedures for business process reengineering include the following steps. 
Step 1. Upgrading the existing information-sharing platform. As mentioned before, the Modeling of an functions of the current information-sharing platform is limited, and some new services should be introduced. For example, each node in the SCPF can register on the platform and interact with each other. According to the proposed model, the workflow of the supply chain is shown in Figure 6.

Step 2. Realizing the real-time information capturing and online monitor. Implementing IoT technologies has been included in the 13th Five-Year Plan (2016-2020) of this company. The proposed model provides a reference for deploying the infrastructure of IoT. The real-time operations of the supply chain can be captured and monitored through the cloud platform. IoT and cloud service platform can implement the monitoring and diagnosing of supply chain operations. The workflow of operation monitoring is shown in Figure 7.

Step 3. Establishing downstream SHIP to dominate the operations of supply chain. IoT supports the visualization of supply chain operations. So, this industrial park tends to expand its business areas, such as providing services related to the management of supply chains,

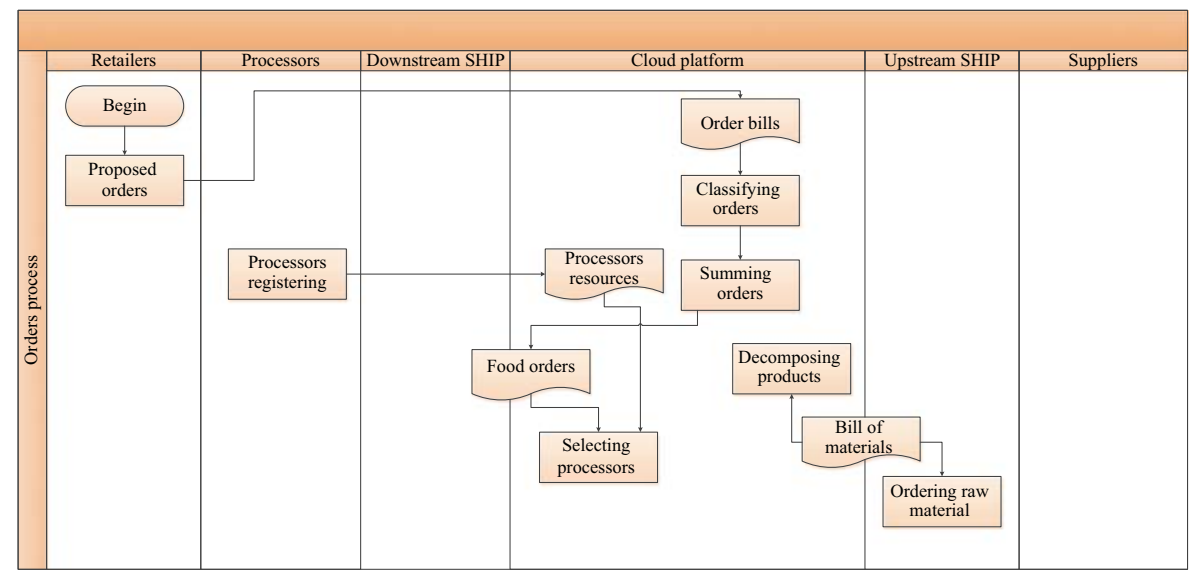

Figure 6.

Workflow of the supply chain based on the proposed models

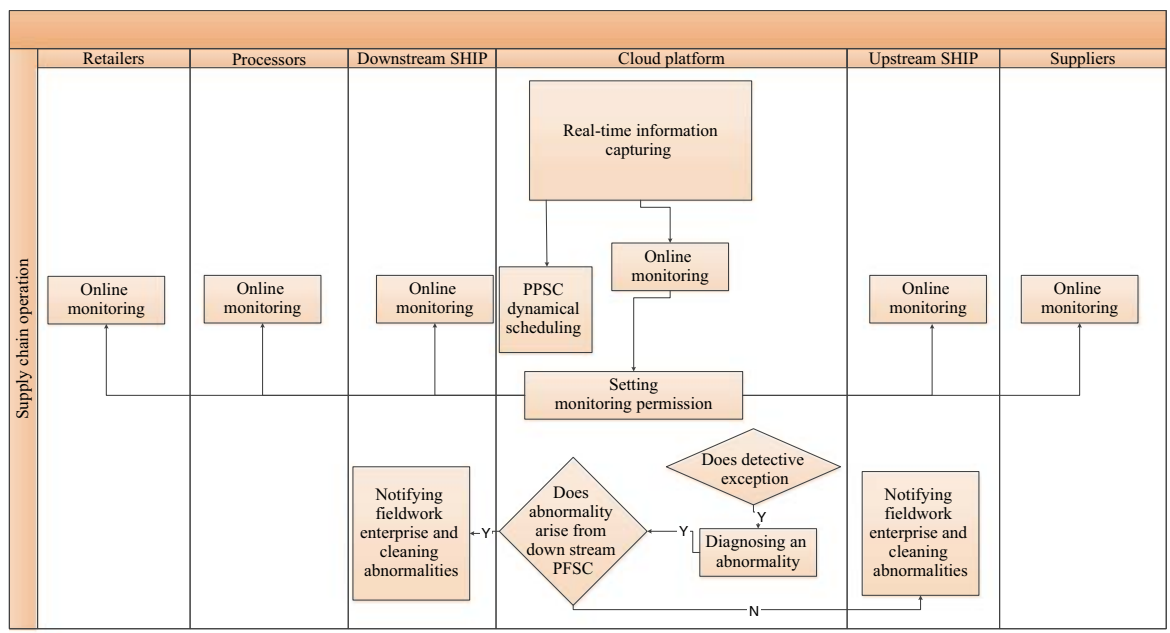

Figure 7.

The flowchart of the monitoring of the supply chain 
IMDS

117,9

1902

integrating logistics service, etc., to pursue more supply chain surplus. The supply hubs which are set up to fulfill these functions participate in the supply chain operations. The storage area of the case company is transformed into a supply hub. Figure 8 shows the plan of the rebuilt industrial park. The functional areas such as aquatic product area, fresh fruit area, vegetable area, etc., are designated.

To achieve more supply chain surplus, it is considered that the supply hub empowered as the dominator of the operations in downstream supply chain. A sand table which simulates the SHIP scenario is shown in Figure 9, where the internal layout of supply hubs and the related logistics activities are present. The order-processing center acting as an independent unit in SHIP is not only intended to process orders, but also for assigning different orders to different processors.

Step 4. Establishing the upstream SHIP. The scale effect and the brand value of this industrial park enhance the influence of the upstream SHIP in the supply chain, which is beneficial for developing and maintaining supply chain relationships. During the implementation of this step, if a SHIP already exists in the upstream supply chain, it is relatively easy to promote closer cooperation within the SHIP. Otherwise, the scale effect and the brand value are the initial forces to the establishment of a new SHIP.

\section{Conclusions and future work}

Currently, the perishable food industry need to establish an efficient and quick-respond supply chain with low cost to meet the challenge of keeping the perishable food fresh even in cross-regional cases. A conceptual model was established for the perishable food supply

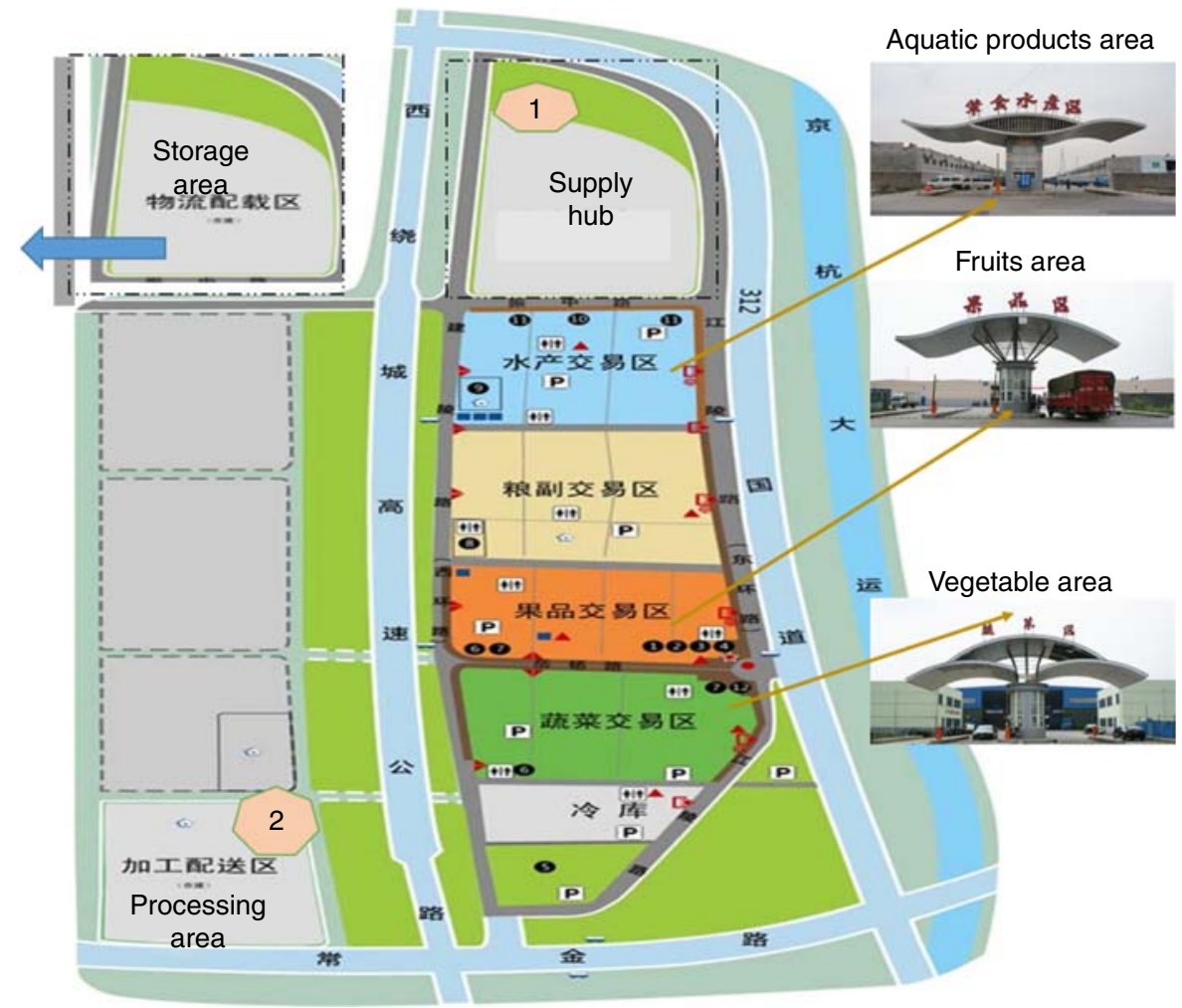

Figure 8.

Plan of the rebuilt industrial park 


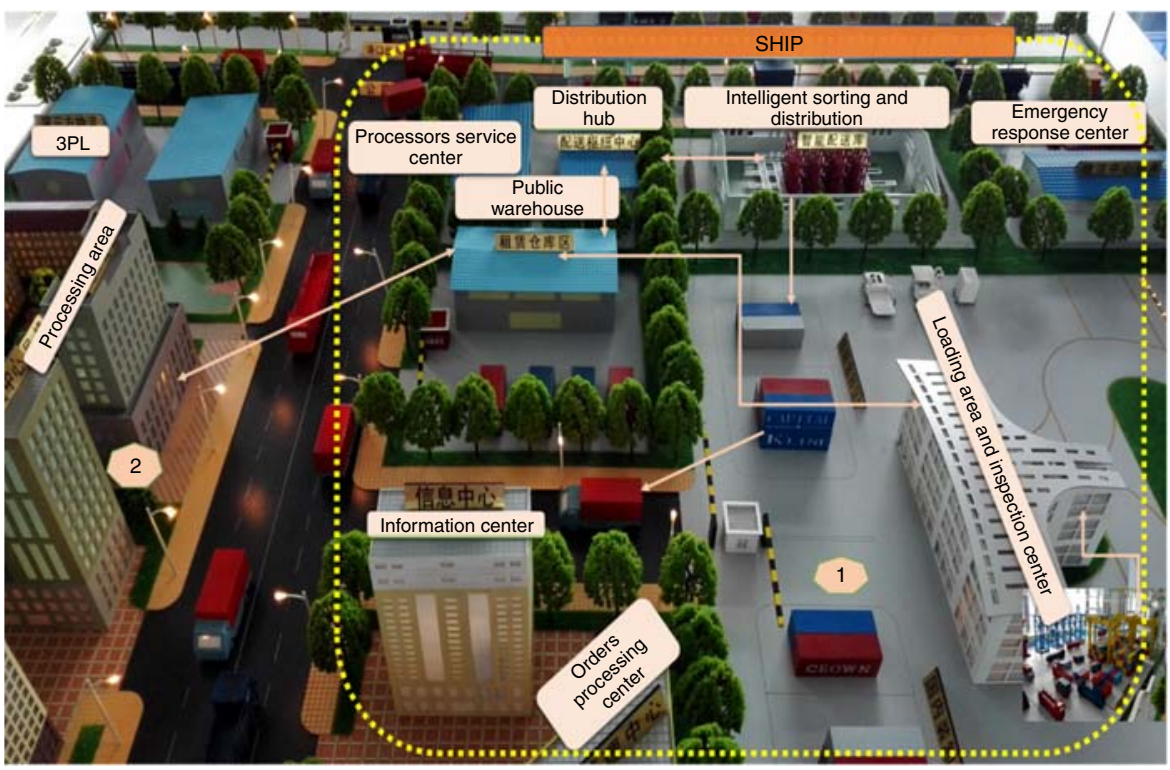

Modeling of an IoT-enabled SCPF-2ESH

1903

Figure 9.

The internal layout of SHIP and its related logistics activities

chain with 2ESH. In order to realize the real-time information sharing among different roles in a supply chain, an easy-to-deploy and simple-to-use architecture for SCPF is developed by applying the IoT technologies. In our research, the IoT-enabled SCPF has two supply hubs which dominate the operations in the supply chain. The two hubs respond to their nearby nodes of the supply chain. They can provide public warehousing and logistic services, and can also be used for online operational monitoring and emergency treatment. The performance of supply chain has improved when implementing the proposed model, as is demonstrated by the case study.

There are four main contributions presented in this work. First, an overall architecture of IoT is constructed to achieve the information sharing within the supply chain. The architecture can act as a reference model when applying IoT in such industries. Second, the model of perishable food supply chain with two supply hubs is designed to optimize the performance of SCPF. Third, the real-time information-sharing mechanism redefines the ways to select processors in SCPF-2ESH, since the information asymmetry between different roles in the supply chain is turned into information symmetry under the IoT environment. A processors satisfaction-based processor selection model is also proposed to allocate orders. Finally, a representational case is shown to demonstrate the workflow of SCPF after applying this model.

The future work will mainly focus on the extension of self-organizing and online dynamic scheduling in cloud platform, so that the proposed model will be more robust and reliable under complex situations.

\section{References}

Atzori, L., Iera, A. and Morabito, G. (2010), "The Internet of Things: a survey", Computer Networks, Vol. 54 No. 15, pp. 2787-2805.

Aung, M.M. and Chang, Y.S. (2014), "Traceability in a food supply chain: safety and quality perspectives", Food Control, Vol. 39, pp. 172-184. 
IMDS 117,9

Baldwin, R., Venables, A.J. and Bridgman, B. (2012), "Global supply chains: why they emerged, why they matter, and where they are going", Journal of International Economics, Vol. 90 No. 1, pp. 245-254.

Barnes, E., Dai, J., Deng, S., Down, D., Goh, M., Lau, H.C. and Sharafali, M. (2000), "On the strategy of supply hubs for cost reduction and responsiveness", white paper, School of Industrial and Systems Engineering, Georgia Institute of Technology, Atlanta.

Bosona, T. and Gebresenbet, G. (2013), "Food traceability as an integral part of logistics management in food and agricultural supply chain", Food Control, Vol. 33 No. 1, pp. 32-48.

Bowersox, D.J., Closs, D.J. and Cooper, M.B. (2007), Supply Chain Logistics Management, McGraw-Hill. Davenport, T.H. (1995), "Reengineering a business process”, Harvard Business School, Vol. 44, p. 16. de Saint-Exupery, A. (2009), "Internet of things strategic research roadmap”, Strategic Research Agenda [SRA], available at: http://ec.europa.eu/information_society/policy/rfid/documents/in_cerp.pdf

Denolf, J.M., Trienekens, J.H., Wognum, P.M., Van Der Vorst, J.G.A.J. and Omta, S.W.F. (2015), "Towards a framework of critical success factors for implementing supply chain information systems", Computers in Industry, Vol. 68, pp. 16-26.

Eksoz, C., Mansouri, S.A. and Bourlakis, M. (2014), "Collaborative forecasting in the food supply chain: a conceptual framework", International Journal of Production Economics, Vol. 158, pp. 120-135.

Ergen, E., Akinci, B. and Sacks, R. (2007), "Life-cycle data management of engineered-to-order components using radio frequency identification”, Advanced Engineering Informatics, Vol. 21 No. 4, pp. 356-366.

Giusto, D., Iera, A., Morabito, G. and Atzori, L. (2010), The Internet of Things: 20th Tyrrhenian Workshop on Digital Communications, Springer, available at: https://doi.org/10.1007/978-1-4419-1674-7

Grunow, M. and Piramuthu, S. (2013), "RFID in highly perishable food supply chains - remaining shelf life to supplant expiry date?", International Journal of Production Economics, Vol. 146 No. 2, pp. 717-727.

Hong, I.-H., Dang, J.F., Tsai, Y.-H., Liu, C.-S., Lee, W.-T., Wang, M.-L. and Chen, P.-C. (2011), “An RFID application in the food supply chain: a case study of convenience stores in Taiwan", Journal of Food Engineering, Vol. 106 No. 2, pp. 119-126.

Hou, J.-L. and Huang, C.-H. (2006), "Quantitative performance evaluation of RFID applications in the supply chain of the printing industry", Industrial Management \& Data Systems, Vol. 106, pp. 96-120.

Iakovou, E., Vlachos, D., Achillas, C. and Anastasiadis, F. (2014), "Design of sustainable supply chains for the agrifood sector: a holistic research framework", Agricultural Engineering International: CIGR Journal, Special issue, pp. 1-10.

Kim, K., Jeong, B. and Jung, H. (2014), "Supply chain surplus: comparing conventional and sustainable supply chains", Flexible Services and Manufacturing Journal, Vol. 26 Nos 1-2, pp. 5-23.

Korpela, J., Kyla, K., Lehmusvaara, A. and Tuominen, M. (2002), "An analytic approach to production capacity allocation and supply chain design”, Risk Analysis, Vol. 78 No. 2, pp. 187-195.

Leung, J., Cheung, W. and Chu, S.C. (2014), "Aligning RFID applications with supply chain strategies”, Information and Management, Vol. 51 No. 2, pp. 260-269.

Li, S. and Qiu, J. (2014), "Financial product differentiation over the state space in the mutual fund industry", Management Science, Vol. 60 No. 2, pp. 508-520.

Porter, M.E. and Heppelmann, J.E. (2014), "How smart, connected products are transforming competition", Harvard Business Review, Vol. 92 No. 11, pp. 64-88.

Qiu, X. and Huang, G.Q. (2013), "Supply Hub in Industrial Park (SHIP): the value of freight consolidation", Computers and Industrial Engineering, Vol. 65 No. 1, pp. 16-27.

Qiu, X., Huang, G.Q. and Lam, J.S.L. (2014), "A bilevel analytical model for dynamic storage pricing in a Supply Hub in Industrial Park (SHIP)", IEEE Transactions on Automation Science and Engineering, Vol. 12 No. 3, pp. 1017-1032.

Qiu, X., Luo, H., Xu, G., Zhong, R. and Huang, G.Q. (2015), "Physical assets and service sharing for IoT-enabled Supply Hub in Industrial Park (SHIP)", International Journal of Production Economics, Vol. 159, pp. 4-15. 
Qu, T., Chen, Y.D., Wang, Z.Z., Nie, D.X., Luo, H. and Huang, G.Q. (2015), "Internet-of-Things-based Modeling of an just-in-time milk-run logistics routing system", 12th International Conference on Networking, Sensing and Control, IEEE, pp. 258-263.

Saguy, I.S., Singh, R.P., Johnson, T., Fryer, P.J. and Sastry, S.K. (2013), "Challenges facing food engineering", Journal of Food Engineering, Vol. 119 No. 2, pp. 332-342.

Soto-Silva, W.E., Nadal-Roig, E., González-Araya, M.C. and Pla-Aragones, L.M. (2016), "Operational research models applied to the fresh fruit supply chain", European Journal of Operational Research, Vol. 251 No. 2, pp. 345-355.

Tsolakis, N.K., Keramydas, C.A., Toka, A.K., Aidonis, D.A. and Iakovou, E.T. (2014), “Agrifood supply chain management: a comprehensive hierarchical decision-making framework and a critical taxonomy”, Biosystems Engineering, Vol. 120, pp. 47-64.

Uckelmann, D., Harrison, M. and Michahelles, F. (2011), "An architecture approach towards the future Internet of Things", Architecting the Internet of Things, pp. 1-24.

Zhang, Y., Wang, J. and Liu, Y. (2017), "Game theory based real-time multi-objective flexible job shop scheduling considering environmental impact”, Journal of Cleaner Production, Vol. 167, pp. 665-679.

Zhang, Y., Qu, T., Ho, O. and Huang, G.Q. (2011), "Real-time work-in-progress management for smart object-enabled ubiquitous shop-floor environment", International Journal of Computer Integrated Manufacturing, Vol. 24 No. 5, pp. 431-445.

Zhang, Y., Qian, C., Lv, J. and Liu, Y. (2017), "Agent and cyber-physical system based self-organizing and self-adaptive intelligent shopfloor", IEEE Transactions on Industrial Informatics, Vol. 13 No. 2, pp. 737-747.

Zhang, Y., Wang, J., Liu, S. and Qian, C. (2017), "Game Theory Based Real-Time Shop Floor Scheduling Strategy and Method for Cloud Manufacturing", International Journal of Intelligent Systems, Vol. 32 No. 4, pp. 437-463.

Zhang, Y., Xi, D., Li, R. and Sun, S. (2016), "Task-driven manufacturing cloud service proactive discovery and optimal configuration method", International Journal of Advanced Manufacturing Technology, Vol. 84 Nos 1-4, pp. 29-45.

Zhang, Y., Zhang, G., Qu, T., Liu, Y. and Zhong, R.Y. (2017), “Analytical target cascading for optimal configuration of cloud manufacturing services", Journal of Cleaner Production, Vol. 151, pp. 330-343.

Zhang, Y., Zhang, G., Du, W., Wang, J., Ali, E. and Sun, S. (2015), "An optimization method for shopfloor material handling based on real-time and multi-source manufacturing data", International Journal of Production Economics, Vol. 165, pp. 282-292.

Zhang, Y., Zhang, G., Wang, J., Sun, S., Si, S. and Yang, T. (2014), "Real-time information capturing and integration framework of the Internet of Manufacturing Things", International Journal of Computer Integrated Manufacturing, Vol. 3052, December, pp. 1-12.

Zhe, L., Yong, G., Hung-Suck, P., Huijuan, D., Liang, D. and Tsuyoshi, F. (2015), "An emergy-based hybrid method for assessing industrial symbiosis of an industrial park", Journal of Cleaner Production, Vol. 114, pp. 132-140.

Zhou, W. and Piramuthu, S. (2015), "IoT and supply chain traceability", 1st International Conference on Future Network Systems and Security, FNSS, Paris, June 11-13.

Zuckerman, A. (2000), “Compaq switches to pre-position inventory model”, World Trade, Vol. 13 No. 4, pp. $72-74$.

Corresponding author

Yingfeng Zhang can be contacted at: zhangyf@nwpu.edu.cn

For instructions on how to order reprints of this article, please visit our website:

www.emeraldgrouppublishing.com/licensing/reprints.htm

Or contact us for further details: permissions@emeraldinsight.com 